\title{
Weaknesses in policy to support technology \\ diffusion: a study of additive manufacturing in South
}

Africa

First Author: Daniel Kunniger

First Author's Affiliation: Gordon Institute of Business Science, University of Pretoria

Email: dkunniger@gmail.com

Mail Address: Gordon Institute of Business Science, 26 Melville Rd, Johannesburg, 2196, South Africa

Physical Address: Gordon Institute of Business Science, 26 Melville Rd, Johannesburg, 2196, South Africa

Second Author: David R Walwyn, Ph.D.

Second Author's Affiliation: Department of Engineering and Technology Management, University of Pretoria

Email: david.walwyn@up.ac.za

Mail Address: The Department of Engineering and Technology Management, University of Pretoria, Private Bag X20, Hatfield, Pretoria 0028, South Africa

Physical Address: Room 2-18, Engineering 2 Building, Hatfield Campus, University of Pretoria, Pretoria, South Africa

Corresponding Author: David R Walwyn, Ph.D.

Corresponding Author's Institution: The Department of Engineering and Technology Management, University of Pretoria

Order of Authors: Daniel Kunniger, David Richard Walwyn 


\section{Abstract}

The South African manufacturing sector has declined significantly as a major contributor to the economy, contracting from $21 \%$ in 1994 to $12 \%$ of Gross Domestic Product in the first quarter of 2016. The stagnation of the manufacturing sector in real terms reflects its fragility and suggests that some sort of intervention is required to prevent its impending decline. It is possible that additive manufacturing, whose global sales could reach $\$ 550$ billion by 2025 , may provide a solution to the problems of the sector. However, there is little information available about the adoption of additive manufacturing, or even more generally about the efficiency of innovation through doing, using and interacting, within South Africa. In this study, a mixed-method design was applied in order to determine the status of additive manufacturing within a specific geographic cluster of the country's main manufacturing province, and to identify factors that are motivating or prohibiting its uptake. A total of 95 companies were surveyed from which 31 responses were obtained. The results were interpreted using descriptive statistics, Key-Words-In-Context analysis and the Bass model of technology diffusion. It was evident that there is limited adoption of additive manufacturing within this cluster with only $5 \%$ of the sample reporting lease or ownership of additive manufacturing devices. No dominant technology has yet emerged within the cluster and the Bass model predicts that the markets full potential may only be reached in 2040. Unfortunately the majority of firms in the sample were either poorly informed or misinformed about the technology, reflecting a general weakness in terms of knowledge, learning and market understanding, all of which are major drivers of innovation. Efforts to support technology diffusion by the Department of Science and Technology through programmes such as the Advanced Manufacturing Technology Strategy may account for the

emergence of the early adopters as revealed by the study. However policy instruments in support of doing, using and interacting, mostly driven by the Department of Trade and Industry, need to be considerably strengthened if further decline of the manufacturing sector is to be avoided. 
Keywords

Additive manufacturing, technological diffusion, South Africa, Bass model. 


\section{Introduction}

South Africa's manufacturing GDP has been largely stagnant since 1994, hovering around a value of ZAR 380 billion (at constant 2010 values), equivalent to about USD 42 billion (at constant 2005 values). As a result the sector has declined significantly as a major contributor to the economy, contracting from $21 \%$ in 1994 to $12 \%$ of Gross Domestic Product (GDP) in the first quarter of 2016 (Statistics South Africa, 2016). As shown in Figure 1, GDP has nearly doubled in real terms over this period whereas manufacturing grew slowly over the period 2000 to 2005 but has since contracted.

Figure 1. South Africa's economic performance normalised according to the 1994 values

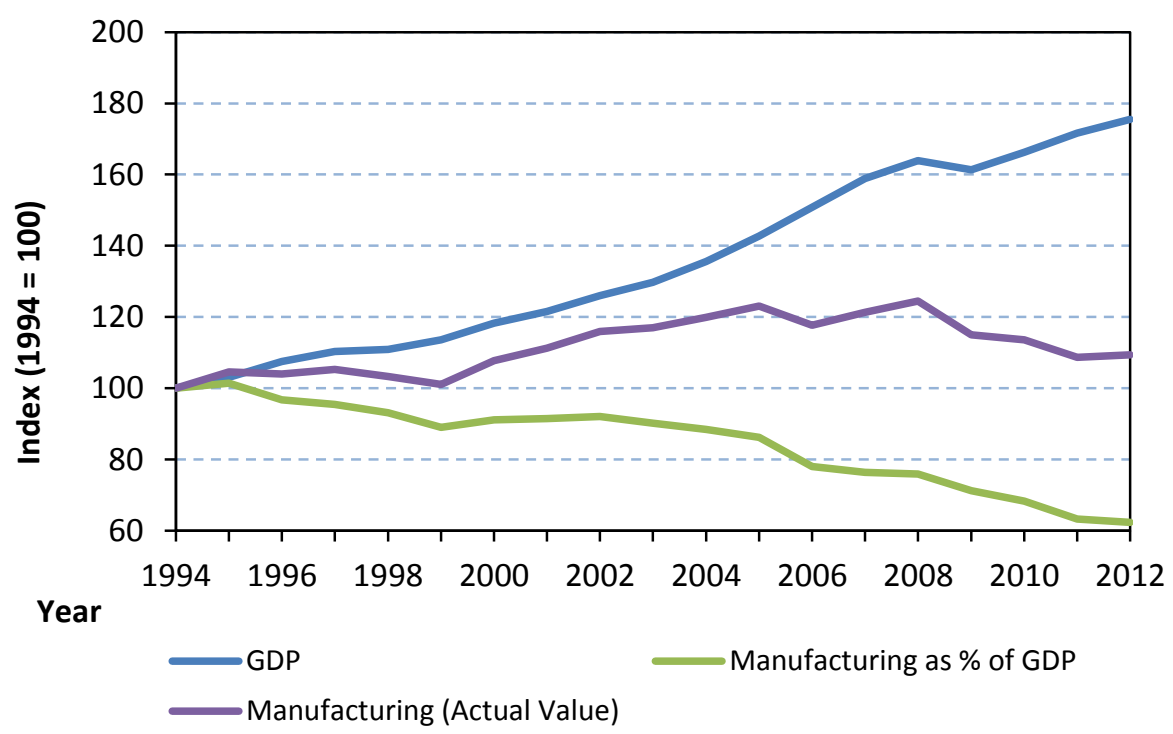

This stagnation, particularly in the medium and high technology sectors, was recognised in the early phases of post-1994 South Africa and became a focus of industrial policy including various versions of the Industrial Policy Action Plan (the dti, 2015). However these initiatives have been largely unsuccessful and economic diversification presents an ongoing and intractable challenge to its government, the latter now desperate to reduce its dependence on the ailing minerals sector and transform a resource-based economy to a learning economy. Path dependence remains a key determinant in the economy with relatively little change in several aspects (Seekings and Nattrass, 2015). The post-apartheid state acquired a system of actors, institutions and policies which had historically paid little 
attention to the key areas of human resource development and the needs of the poor; as a consequence transformation of the economy has been slow to realise (Mariotti and Fourie, 2014) and economic growth has been handicapped by a general skills shortage (Faulkner et al., 2013).

Although human resources are a key constraint, it has also been suggested that innovation policy has been overly focussed on science and technology (S\&T) with relatively little attention to the more critical aspect of innovation through doing, using and interacting (DUI) (Schwab and Sala-i-Martin, 2014). The latter is a key process for developing countries, or catch-up economies such as South Africa, and includes the components of technology transfer, absorption, diffusion and adoption. Although there have been numerous reviews of science and technology policy (Department of Science and Technology, 2012; Kaplan, 2008; OECD, 2007), there have been relatively few studies of the processes of innovation diffusion and absorption. This report is one such study; it is an attempt to understand the nature and extent of these processes in South Africa and hence determine how such processes can be improved.

The diffusion of additive manufacturing (AM) has been chosen as a suitable case study for this analysis. It is noted that this project was conceived as an inductive study with an attempt to theorise the weakness of technology adoption and diffusion within South Africa. AM, more commonly known as 3-D printing, has been publicized as a potentially disruptive technology (Campbell and Ivanova, 2013). Besides its ability to produce items previously impossible to manufacture, it enables on-demand production leading to measurable benefits in supply chain management and stock warehousing, both of which are significant cost drivers for consumables (Manyika et al., 2013). Its choice, therefore, as a case study has been motivated by the early stages of adoption and the technology's potential as a means of transforming the manufacturing sector. AM could provide South African manufacturers with the ability to become competitive in the global manufacturing market through new, more advanced manufacturing capability. 
The article provides an initial overview of the technology and theories of diffusion. This section is then followed by a detailed discussion of the methodology, the conceptual model and the results.

\section{Literature Review}

\subsection{Models of Diffusion}

In this article, it will be assumed that technology adoption applies at the level of an individual who may consider the acceptance or rejection of a particular innovation (Straub, 2009). Diffusion, on the other hand, refers to the movement of an innovation through a social system. In this sense, adoption is considered as happening predominantly at a micro level focused on change within specific contexts whilst diffusion is a macro perspective looking at the spread of innovation within a sector or industry over time (Straub, 2009).

There are a number of models in the literature for technology adoption. Perhaps the most widely used model, the Rogers model, considers the adoption process as the innovationdecision process, where the latter comprises of five steps namely knowledge, persuasion, decision, implementation and confirmation (Rogers, 2003). Diffusion on the other hand requires the existence of a number of fundamental elements including the innovation itself, communication through certain channels, time and a social system and is the consequence of the combined actions and interactions of individual adopters (Straub, 2009). The latter are crucial to the diffusion process but adopt different roles depending on context, knowledge and individual risk preference. These roles are generally separated according to the time taken to adopt a new technology with Rogers (2003) suggesting that they be categorised into innovators, early adopters, early majority, late majority and laggards.

By modelling the behaviours of these individual groups, it is possible to generate the typical S-shaped curve of technology diffusion (see Figure 1). The general form of the Sshaped curve is referred to as the logistic function, which is defined by the following mathematical equation: 


$$
f(x)=\frac{L}{1+e^{-k\left(x-x_{0}\right)}}
$$

where:

- $f(x)$ is the $y$-values making up the logistic function.

- $x_{0}$ is the $x$-value of the sigmoid midpoint.

- $\quad x$ is the $x$ values in the real number domain.

- $\quad L$ is the maximum value the curve will achieve.

- $e$ is the natural logarithm.

- $\quad k$ is the slope of the curve.

\section{Figure 1. The S-curve of technology diffusion}

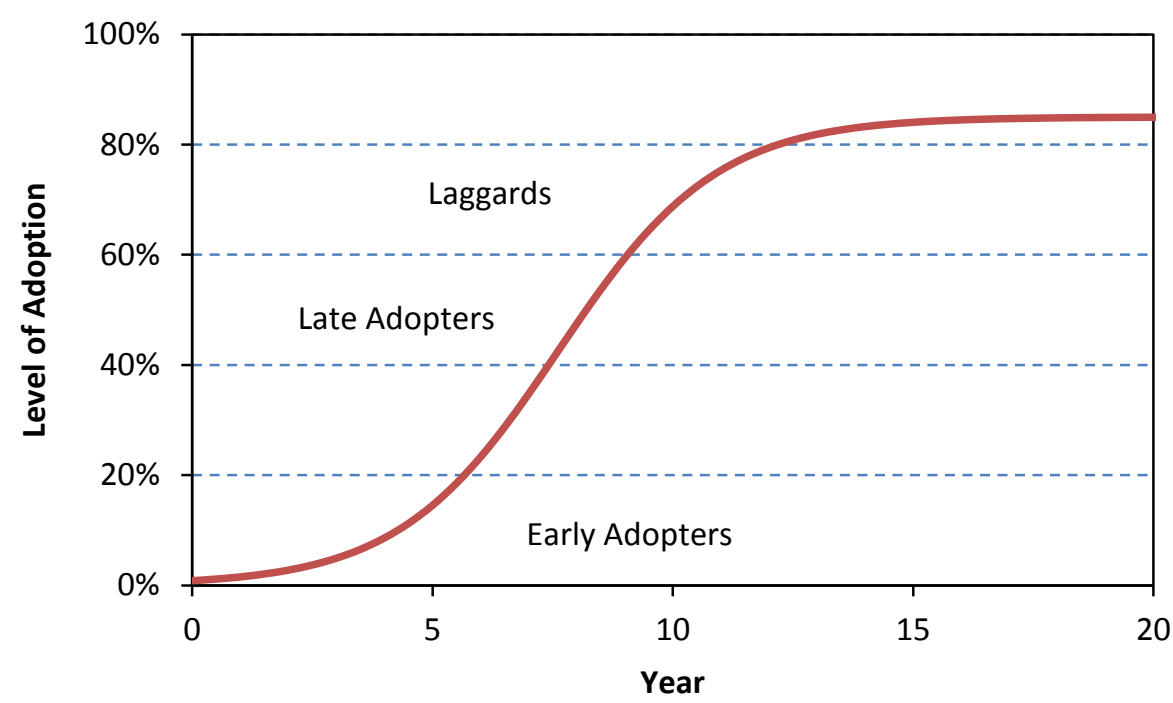

The Rogers model has been criticised on the basis that adoption processes extend beyond the actions of individuals and are influenced by a broad range of factors, particularly at a firm or organisational level (Azarmi, 2016; Oliveira and Martins, 2011; Venkatesh et al., 2003). The latter include social skills and teamwork, firm-level values and culture, openness to knowledge systems, encouragement for innovation and tolerance of failure. Proposed modifications and additions to the model include the following: 
- the innovators perception of the technology (ease of use and perceived usefulness) (Davis, 1989)

- individual user behaviour as determined by performance expectancy, effort expectancy, social influence and facilitating conditions, and moderated by gender, age, experience and voluntariness; this addition was defined as the united theory of acceptance and use of technology (Venkatesh and Morris and Davis and Davis, 2003)

- the distinction between the initial stages of adoption (akin to radical innovation) and later modifications to the dominant design (as in incremental innovation) (Abenathy and Utterback, 1978; Akiike, 2013)

- the inclusion of environmental in addition to the organisational and technological roles (Oliveira and Martins, 2011), a model known as the technology, organisation and environment framework and widely adopted within studies of technological innovation.

One of the most influential extensions of the Rogers model has been the development of the Bass Model, initially developed to describe the adoption of new consumer products (Bass, 2004). Bass re-categorized the five categories of adopters in the Rogers model as a single class of innovators (Rogers Category 1 ) and 4 classes of imitators (Rogers Categories 2 through 5). He then postulated that the probability of a purchase by the imitators was linearly proportional to the number of previous buyers, resulting in the exponential growth of initial purchases, followed by an exponential decay. The model was shown to accurately forecast the consumption or adoption patterns of consumer durable goods, and later to a much wider class of products and services including telecom services and equipment, component products such as semiconductor chips, medical products, and many other technology-based products and services.

Since the original development of the Bass model, subsequent extensions have been developed, including the diffusion of successive generations of technology (Norton and Bass, 1987), the introduction of a pricing variable (Robinson and Lakhani, 1975), and much later the Generalized Bass Model which incorporated the shifting of the curve concept (Bass 
et al., 2001). The change led to the expression of an equation commonly referred to as the Bass Model Principle, as shown in Equation 2.

$$
\frac{f(t)}{1-F(t)}=p+\frac{q}{M}[A(t)]
$$

Although the Bass Model Principle can provide insight into the possible diffusion of products and technologies, it is still a function of a set of input parameters and it is important to understand the scope of these variables, including:

- $\quad p$ the coefficient of innovation.

- $q$ the coefficient of imitation.

- $\quad M$ the potential market (the ultimate number of adopters).

Lilien \& Rangaswamy (2007) stated that there are several methods of determining the input parameters to the Bass model. These methods could be categorised based on the reliance of historic data or judgement for calibrating the model. Examples of this would be the use of linear or non-linear regression if historic sales data is available or analogues and survey data to determine customer purchase intentions (Judgement method).

Bass presents a method of determining the three input parameters in the original paper in which he presents his model (Bass, 2004). The method makes use of a discrete analogue. Bass begins with Equation 3, which is a manipulated version of the Bass Model Principle:

$$
a(t)=M p+[q-p] A(t)-\frac{q}{M} A(t)^{2}
$$

where $a(t)$ is the adopters at time t. The equation is a normal quadratic as a function of $A(t)$ which can be solved using standard approaches for the parameters $M, p$ and $q$, as long as some initial sales data is available (at least three observations). 
The Bass Model Principle has been applied substantially since its introduction in 1967 and values for the input parameters depending on the type of product have been published (Lilien et al., 1999). The consistency of these values across a range of contexts for the same industrial sector is perhaps a minimum test for the overall validity of the model. Disappointingly the parameters are shown to have a high degree of variability, with a large range among the ad-hoc parameter estimates (Massiani and Gohs, 2015). Furthermore the Bass $\mathrm{p}$ parameter appears unstable and is sensitive to the assumed market potential $\mathrm{M}$. When the proposed potential market is not certain, the Bass parameters can vary by factors as high as 100 fold. It was also noted that the Bass $p$ parameter was highly influenced by proposed market potentials (when the market potential was exogenous), while the $q$ parameter was only marginally affected.

Massiani and Gohs (2015) also suggested a two-step parameter selection process. Firstly, select a Bass q parameter value from the Bass Model with exogenous determined market potential. Secondly, determine the Bass $p$ parameter value given $M$ and $q$. If there is insecurity regarding the market potential, determine the $p$ and $M$ values given the $q$ value simultaneously.

These models present a rather linear process of adoption and generally fail to distinguish between the important processes for different types of innovation, such as radical vs incremental. Adoption processes generally follow an S-curve; it is the shape and duration of the curve which is important and neither the Bass nor the Rogers models offer much insight into the respective values of the model parameters. In this respect it is more useful to consider a blend of models which can provide a more comprehensive framework for understanding the constraints and stimulators of diffusion, which is the ultimate objective of this study. For this purpose the conceptual model as indicated in Figure 2 was developed; the framework includes aspects of the Bass model, the Rogers model, the AbernathyUtterback model, and the Oliveira and Martins model. 


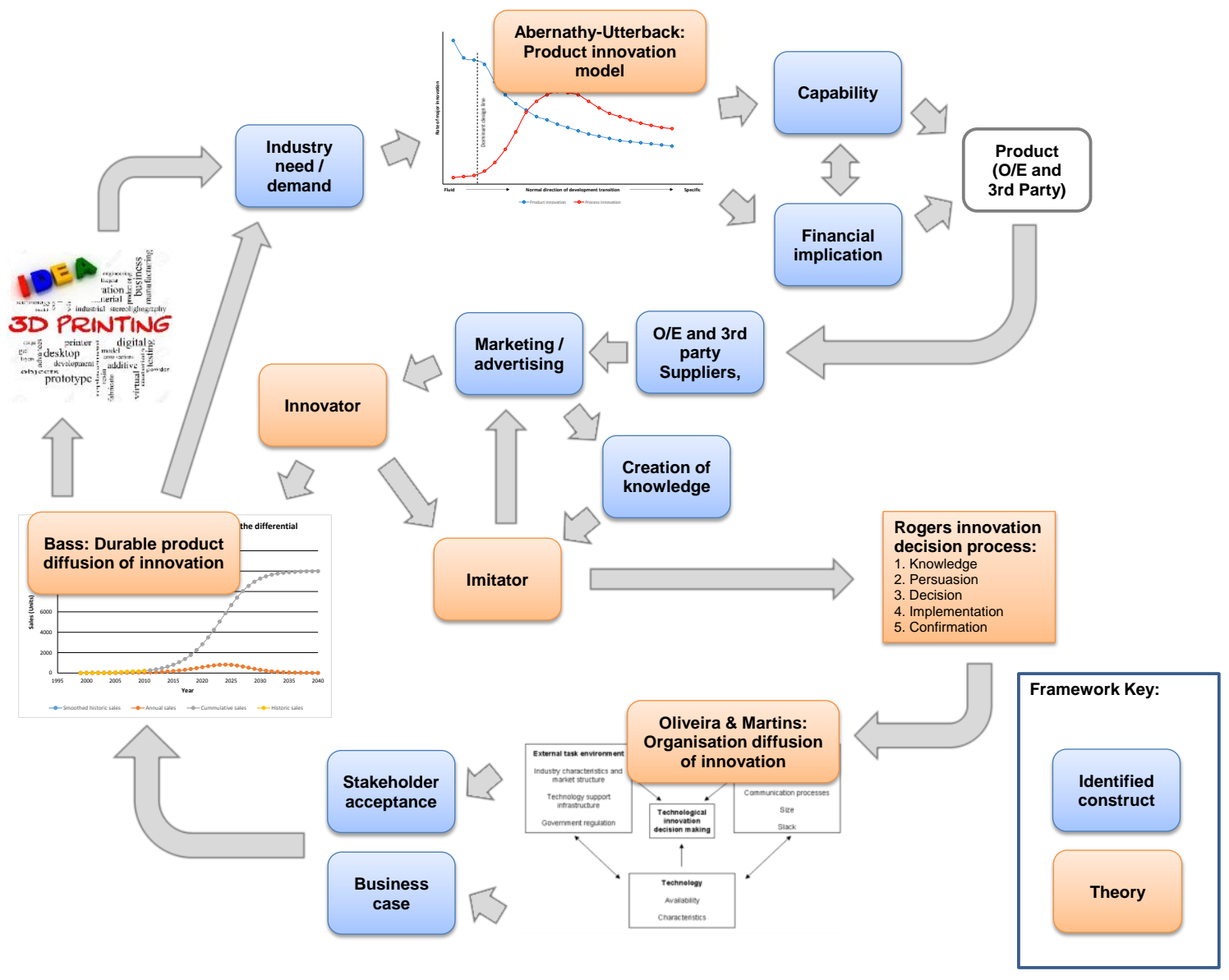

All the approaches share the common element of social cognitive theory, where the latter theory maintains that individuals learn through a process which involves the observation of the behaviour or actions of others within their social context and the replication of this behaviour if the outcome of the initial observation was considered to be positive (Straub, 2009). This aspect is fundamental to understanding the implication of the results from this study.

\subsection{Additive Manufacturing}

AM is the process of fabricating an object through the sequential layering or deposition of material (Budmen et al., 2013; Steenhuis and Pretorius, 2015). Originally the technology could only be applied to plastic products (nylon and polyamides), but has since been extended to a large number of materials including resins, silver, titanium, steel, wax and photopolymers. The technique has several advantages including that it avoids the need for 
the preparation of expensive molds, it can prepare hollow products, it can prepare in one step products which contain one object inside the other or even movable parts (Steenhuis and Pretorius, 2015).

There are four main methods of AM, namely fused filament fabrication, stereolithography, selective laser sintering and laminated object manufacture (Steenhuis and Pretorius, 2015). The market for AM devices is split between direct-to-consumer and the industrial market, with the bulk of the value (and perhaps also the number of devices) still being found in the industrial sector although the consumer market has been growing recently in terms of relative importance.

The major suppliers of industrial machines are Statasys and 3D-Systems, both of the United States. In the consumer market, the dominant suppliers are Makerbot, Flashforge and 3D-Systems (Bashir, 2014).

\subsection{Global Adoption of Additive Manufacturing}

The AM market had an estimated value of $\$ 3.07$ billion worldwide in 2013 , up $34.9 \%$ from 2012 (Conner et al., 2014; Thilmany, 2014). Over its 24-year history the AM industry has grown at an average annual rate of $26 \%$ and the double-digit growth is expected to continue until at least 2019 (De Jong and De Bruijn, 2013) . Cohen (2014) stated that AM had just started to penetrate the market with current estimations of market penetration ranging between $1 \%$ and $10 \%$. He continued to put context to the growth by stating that "compared with traditional manufacturing however, AM production volumes are diminutive, and the technology remains far from gaining mass adoption, especially in direct-part production". He stated that global 3-D printer sales were around $\$ 0.6$ billion while conventional machines tools were around $\$ 90$ billion and plastic processing equipment at $\$ 25$ billion.

According to Geelhoed (2014), key patents expired in February 2014 and further patents on the technology are expiring in the near future; as a result the market is considered to be preparing for further rapid expansion. The market research firm, Canalys, has predicted the 
market to grow to a value of $\$ 16.2$ billion in 2018 (Canalys, 2014). The McKinsey Global Institute predicted that AM could have a global impact of $\$ 550$ billion a year by 2025 (Cohen et al., 2014). The 2016 survey from Wohlers Associates reported the AM industry, consisting of all AM products and services worldwide, grew to $\$ 5.2$ billion in 2015 and the average growth rate for the previous three years was 31.5\% (Caffrey et al., 2016). The present market for devices under $\$ 100,000$ is about $\$ 2.5$ billion, as shown in Figure 3 .

Figure 3. Worldwide growth for 3-D printers under $\$ 100,000$

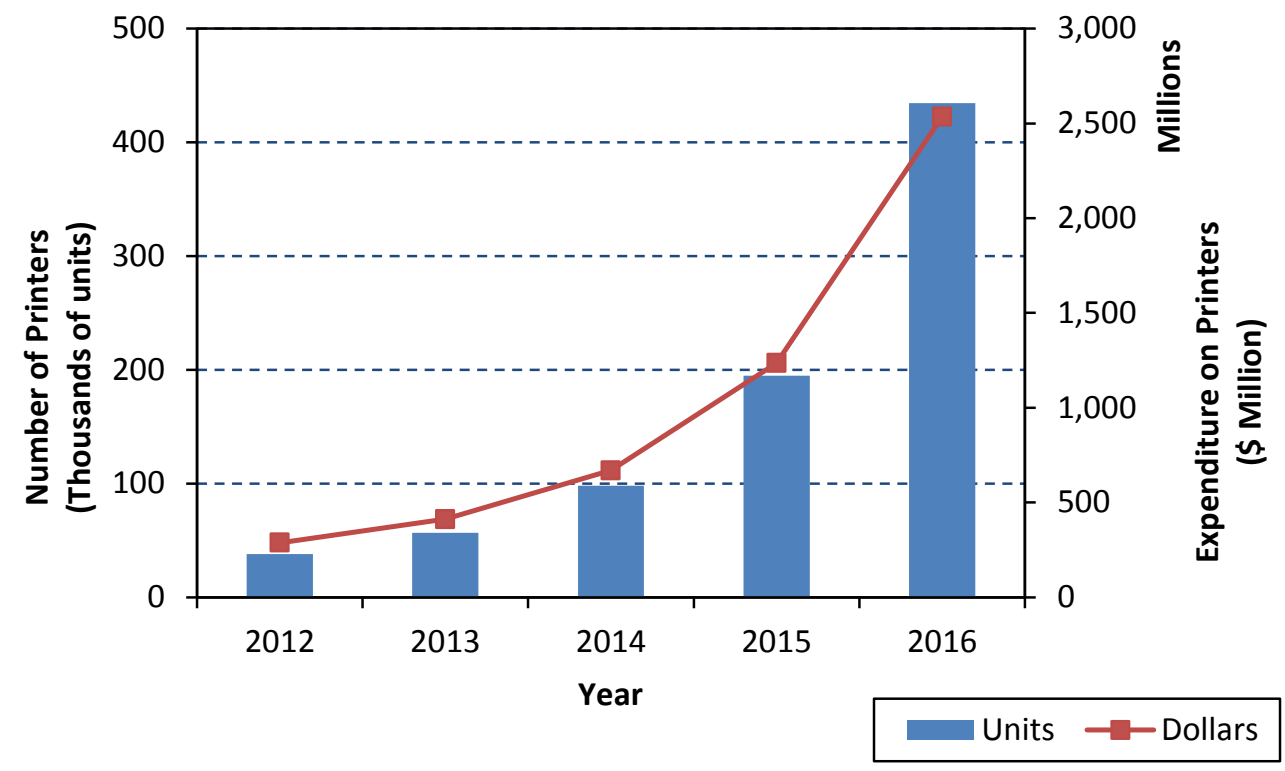

Source: Brown (2014)

In 2014, President Obama announced two new manufacturing innovation institutes supported by a $\$ 140$ million federal commitment combined with more that $\$ 140$ million in non-federal resources. This is just two of the envisioned 45 manufacturing innovation institutes that will help ensure America's future inclusion in the advanced manufacturing sector (The White House, 2014).

Brown (2014), quoting an earlier study, noted that as prices for industrial quality printers had fallen below $\$ 10,000$, many managers could afford to buy such a unit on their own authority to learn about AM technology. On the low-cost side of AM, Brown (2014) indicated that markets were being driven by growth of low-cost printers for schools and 
hobbyists. De Jong and De Bruijn (2013) expected 3-D printing to become part of the mass market. Cohen (2014) suggested technology, awareness and organisational readiness as key contributors to the adoption rate. He also cited McKinsey and Company research showing a general lack in AM applications and value, fuelled by a lack in familiarity of the technology beyond the cover press and the need for potential adopters to learn more about the technology.

Besides purchased machines, the DIY community also appeared to be adopting additive manufacturing. According to De Jong and De Bruijn (2013), Adrian Bowyer created the RepRap in 2005. He shared his design under the GNU license and since then, the design has spawned entire communities. In early 2012 , it was estimated that 29,745 RepRap replicas had been constructed thus presenting the existence of a peer-to-peer network involved in the diffusion of the technology at a grass roots level. In 2012, user-found companies started selling and shipping thousands of these machines annually.

Roth (2014) presented constraints to the diffusion of additive manufacturing. He suggested that due to the linking by suppliers of the machine to the raw material, and the high cost of the latter, it was difficult to build a business case. He further suggested that buyers and suppliers of additive manufacturing machines had different views of 3D printing, which was impeding the diffusion of the technology. Suppliers were too intent on margins at low market volumes, and not cognisant of a longer term need to support the initial development activities within firms, resulting in long-term and much larger markets.

Cohen (2014) indicated that many executives were having difficulty deciding on the technology due to second-order effects on operations and economics. Weller et al. (2015) supported this and stated that even with all the hype around the topic, little research exists on the economic and business effects of additive manufacturing technology, with most academic literature focussed on the technological rather than the techno-economic aspects of AM. 


\subsection{Diffusion of Additive Manufacturing in South Africa}

According to Du Preez and De Beer (2006), the first rapid prototyping machines in South Africa were imported in 1994. A few years later the Rapid Product Development Association of South Africa was formed and has played a critical role in raising awareness through an annual conference and international ties such as the Global Alliance of Rapid Prototyping Associations.

According to De Beer (2008), only one South African firm owned a rapid prototyping machine in 1998. However significant adoption was experienced by 2004 as can be seen in Figure 4.

Figure 4. Number of rapid prototyping machines in South Africa

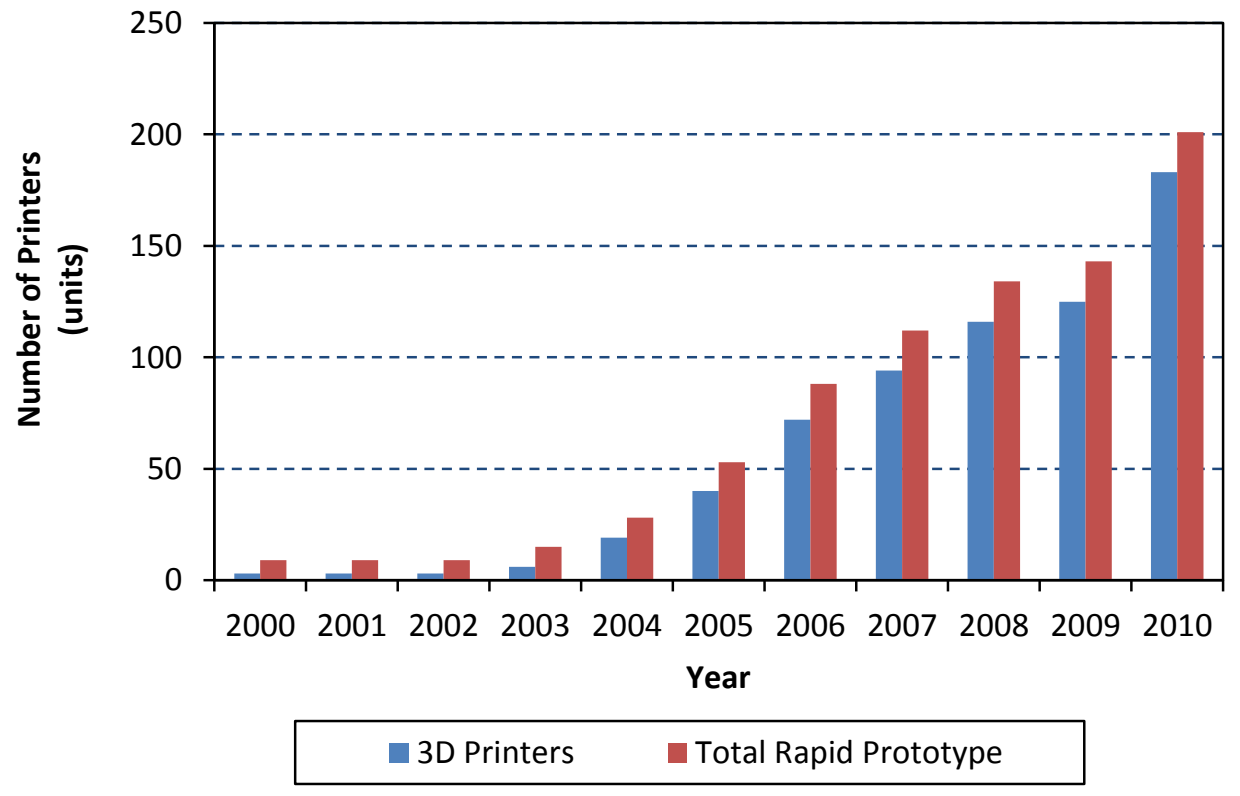

Source: Du Preez (2011)

Campbell et al. (2011) stated that by the end of 2005, 74\% of the rapid prototyping machines in South Africa were privately owned. By the end of $2008,88 \%$ of these devices were of 3-D printer type. However this study only acknowledged the low-cost low-capability and the high-cost high-capability market segments. They estimated that the market was $54 \%$ (by machine cost) high-cost high-capability machines and the remainder of low-cost 
low-capability type. Wild (2014) stated that recent Rapid Product Development Association of South Africa estimates placed the number of low-end machines in South Africa at approximately 1,400 and high-end machines at approximately 300 .

According to DefenceWeb (2013), there is some local manufacture of AM machines. This study indicated that Boeing and the Council for Scientific and Industrial Research were developing a large-scale titanium AM machine for use in the aviation industry with support from the Department of Science and Technology. Wild (2014) noted that the Department of Science and Technology, together with CSIR, academia and industry, had also begun to develop an AM technology road map to set the direction for South African manufacturing firms, although this document has not yet been finalised. In addition to the lack in clarity surrounding this plan, Campbell and De Beer and Pei (2011) identified the following weaknesses and threats:

- available systems (machines) and raw materials for these systems are limited

- fabrication times are considered to be longer and not shorter

- major South African industries are not embracing AM due to dependence on product designs from companies outside of the country

- there is a lack of applied research in the universities to support the necessary skills and technology transfer.

\section{Methodology}

This study set out to understand the diffusion of AM in the manufacturing hub of South Africa, Gauteng. Existing literature suggested that the technology was being applied but only at an experimental level but the studies themselves offered little insight into the factors preventing the use of $\mathrm{AM}$ as a means of transforming the manufacturing sector (Campbell and De Beer and Pei, 2011). In this study the following research questions were explored in order to provide this insight: 
- participation: to what extent has AM been adopted in the Gauteng manufacturing sector outside of the public research institutions?

- drivers: what (social and economic) factors are driving or hindering the adoption of AM?

- $\quad$ preference: has a dominant design of AM machinery emerged?

- future rate of adoption: what is the predicted rate of diffusion of AM?

\subsection{Sample Selection and Data Collection}

The population was chosen as firms operating in the Gauteng manufacturing sector, with the respondents being individuals currently employed within the firms but not necessarily representing the views of the firm. The sampling technique was cluster-based purposive sampling. A single industrial area (Sebenza) was selected within the Gauteng province and all firms listed on the internet as having an address in that area were entered into a database. Additional members of the sample frame were then identified by the researcher a street-level physical search. In this way the names and addresses of 121 firms were obtained.

Each firm was then contacted and an existing employee, with knowledge of product development within the company, identified. Furthermore the activities of the firm were checked to ensure that the firm could be classified as a manufacturing entity. The online research tool Survey Monkey was then used to generate a questionnaire, which was tested in an initial pilot study using respondents not within the sample frame, but within the population in general (all manufacturing companies in Gauteng). The responses as well as a direct feedback session were used to improve the questionnaire in terms of clarity and construct validity.

From the 121 companies originally identified as manufacturing companies, only 95 were confirmed upon enquiry as manufacturing companies. Respondents from these firms were then requested to complete the survey. An e-mail with a link to the survey was provided 
and receipt thereof was confirmed. Only a single respondent from each organisation was targeted in order to avoid a bias effect of multiple respondents from a single organisation.

\subsection{Experimental Design and Data Analysis}

The conducted research used a mixed-methods design, with the questionnaire including both quantitative and qualitative questions. This design was considered appropriate since the project was focused at an exploratory level, with an attempt to understand at a general level only the reasons for the limited uptake of AM.

Due to the fact that no hypothesises or propositions were being tested, descriptive statistics were used to present information. This was achieved by converting data obtained using the questionnaire into coded data which was then used for the descriptive statistics. To generate further insight, binary logic (and, or operators) were regularly applied to multiple categories of the quantitative data to obtain focused answers. An example of this would be a respondent that made use of $A M$ and researched AM.

Qualitative data was processed using the Key-Words-In-Context method to identify themes. These themes were later assessed as possible constructs or they were used to provide insight from the responses on the research questions. Such an approach is supported in the literature hermeneutics, where word-based techniques are considered efficient in the early stages of theme identification (Ryan and Bernard, 2003).

Following the processing of both quantitative and qualitative data into information, this information was then consolidated and used to develop the constructs, which were in turn used to answer the research questions.

\section{Results}

As noted earlier, the survey was sent to 95 respondents. Fifteen respondents immediately declined to take part, citing either lack of relevance to their business or adequate 
knowledge of the subject. Although the remainder agreed to participate in the study, only 31 respondents actually returned a completed questionnaire, equivalent to a response rate of $33 \%$. The respondents were well distributed across a range of industry sub-sectors as shown in Figure 5.

Figure 5. Sub-sectoral distribution of respondents

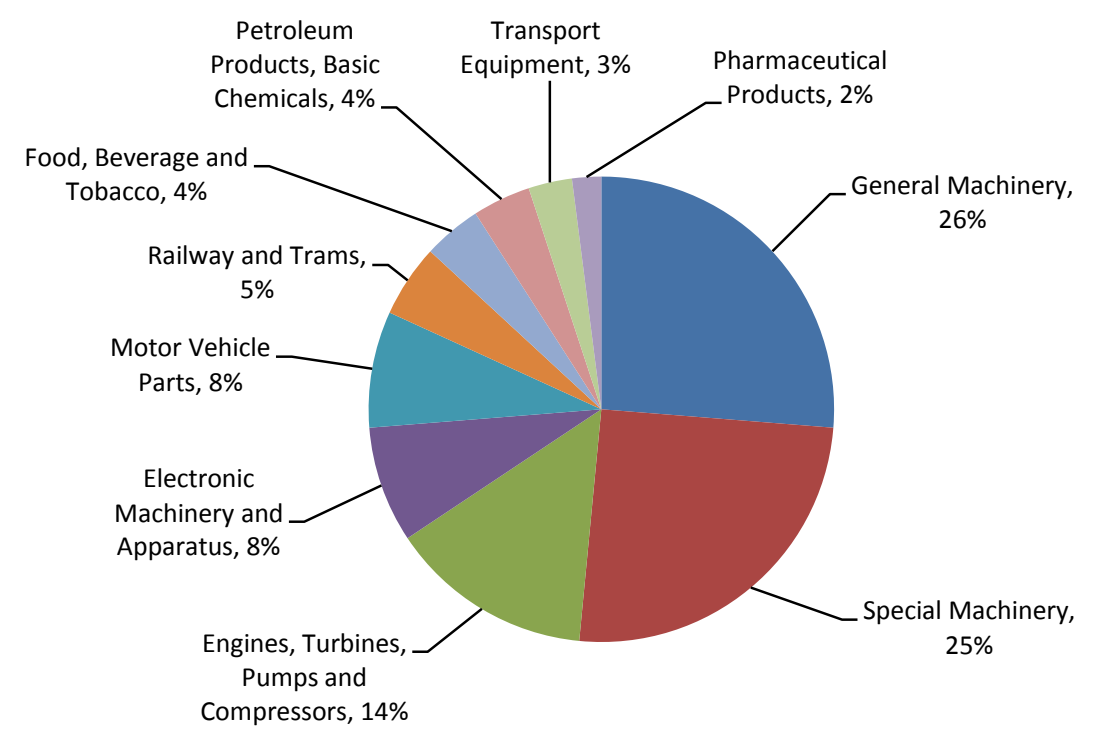

The initial question of the study aimed to determine the status of AM within a major manufacturing hub of South Africa and to identify factors that are promoting or prohibiting the uptake of this technology. It is evident that diffusion within the specific location of this study has been limited with only $16 \%$ of respondents indicating that their firms leased or owned an AM machine. Moreover there was likely to have been a high level of selfselection in the survey responses with the implication being that only $5 \%$ of the sample leased or owned an AM machine. Despite low levels of use, the level of awareness is high with $48 \%$ of respondents ( $16 \%$ of the sample) being aware of the technology.

It was apparent from the responses that the reason for the low level of adoption is the perception that AM fails to offer a cost advantage for routine production over existing technologies. Respondents did recognise the technology's potential to expand their capability into new products, but considered that the demand for such products was still 
limited. When questioned on the potential role and value-add of the technology, the most common key-word-in-context used by respondents was 'prototyping', with $42 \%$ of respondents believing that AM could most beneficially be used as a prototyping tool. Other supporting factors included speed (23\%) and ability to manufacture complex components.

The most prominent negative factor was incompatibility with the required material of construction (13\%) and a lack of general demand from the manufacturing sector for the specific components which can suitably be made using AM. A full list of the perceived positive and negative factors associated with AM is given in Table 1.

Table 1. Perceived positive and negative aspects of AM technology

\begin{tabular}{|c|c|c|c|}
\hline & $\begin{array}{c}\text { No of } \\
\text { Respondents }\end{array}$ & $\begin{array}{l}\text { Proportion of } \\
\text { Respondents }\end{array}$ & $\begin{array}{c}\text { Proportion of } \\
\text { Sample }\end{array}$ \\
\hline \multicolumn{4}{|l|}{ Positive Aspects } \\
\hline Prototyping (Application) & 13 & $14 \%$ & $42 \%$ \\
\hline Speed & 7 & $7 \%$ & $23 \%$ \\
\hline Complex Components & 3 & $3 \%$ & $10 \%$ \\
\hline Space Utilisation & 3 & $3 \%$ & $10 \%$ \\
\hline Lower Cost & 2 & $2 \%$ & $6 \%$ \\
\hline
\end{tabular}

\section{Negative Aspects}

\begin{tabular}{llll}
\hline Incorrect Material Compatibility & 7 & $7 \%$ & $23 \%$ \\
\hline Lack of Geometric Suitability & 2 & $2 \%$ & $6 \%$ \\
\hline Higher Cost & 2 & $2 \%$ & $6 \%$ \\
\hline Component Quantity & 2 & $2 \%$ & $6 \%$ \\
\hline No Demand by Industry & 2 & $2 \%$ & $6 \%$ \\
\hline Developed at Alternative Location & 1 & $1 \%$ & $3 \%$ \\
\hline Technology Unproven & 1 & $1 \%$ & $3 \%$ \\
\hline Unsuitable for Bespoke & 1 & $1 \%$ & $3 \%$ \\
Components & & &
\end{tabular}

Machine capability is apparently both a positive and negative motivator for the adoption of $\mathrm{AM}$, with the major concerns being inadequate component size and lack of material 
capability. Many respondents stated that their companies use steel as the primary raw material and are awaiting the introduction of cost-effective AM machines capable of manufacturing such components at larger scale before investing in the technology.

There appear to be many misperceptions and a general lack of knowledge of machine capability, with only $23 \%$ of the respondents being able to explain common terms in AM such as binder jetting, direct energy deposition, material extrusion and material jetting, and $26 \%$ believing that AM could manufacture a product of equivalent quality to their present outputs. The research also revealed that the cost structure of AM is not well understood, including both direct and indirect costs. Raw material costs are assumed to be expensive as they are imported and beneficiated in the form of different formulations such as extrusion and powderisation.

Roth (2014) reported that suppliers and purchasers of AM equipment have different views about the value of these machines. Similarly it has been evident from this study that there are conflicting viewpoints on the supply of material. Respondents expect to purchase material from third party material suppliers and not the machine supplier, as is currently the norm for materials used by traditional manufacturing equipment. However, it appears that local machine suppliers are following the same model as paper printer manufacturers, which supply both machine and material, an arrangement is seen as potentially exploitative by purchasers of AM equipment.

It is also apparent that marketing in the form of advertisements has been a major influence on the opinion of respondents, affecting perceptions of machine cost versus performance, as well as their perceptions of brand versus generic products. Given that this study undertook to identify constraints only, rather than establish causality or directionality, further exploration of this influence was not tested or proven. However accepting knowledge and persuasion are the first two steps of the innovation decision process, as proposed by Rogers (2003), it is unlikely that the diffusion of AM technology will proceed beyond the early adopters within this environment of limited available information. 
The study also revealed that two key constraints needed to be addressed in relation to the adoption of AM, namely the financial justification (business case) and the favourable alignment of key stakeholders. Many respondents believed senior individuals within their companies would resist the change, which is a common response to the introduction of new technology.

In terms of dominant designs or technologies, the results indicate a wide diversity of technologies both available and in use, and that no single technology has yet become dominant. Following the approach of the Abernathy-Utterback model, which asserts that there is a pivotal change in development focus once a dominant technology has been established, it is clear that it is only the early adopters are experimenting with $A M$ and diffusion is in its early stages only.

Finally adoption was modelled using the Bass Model Principle and historic sales data compiled by Du Preez and De Beer (2006). Initial estimates of the model coefficients were obtained by using the parameters for the diffusion of scanners in retail stores (Bass et al., 2001). This selection was based on similarities in the five areas of environmental context, market structure, buyer behaviour, marketing mix strategies of firms and the characteristic of the innovation (Lilien and Rangaswamy and Van den bulte, 1999). As the market potential $M$ was unknown, the value was iteratively adjusted until the error on the modelling of the historic machine count was minimised. A market potential of 927 units $\left(r^{2}\right.$ of 0.914 ) was found to be the best fit. The resultant model showed an increase in the rate of diffusion of the AM machines until 2023 after which the rate of diffusion will slow until the maximum market penetration is achieved in 2045.

\section{Discussion}

The urgency for South Africa to increase the competitiveness and hence GDP contribution of its manufacturing sector is clearly apparent. The success thereof will have important and positive consequences, not just in terms of job creation and economic growth, but also in providing the necessary stimulus for learning by all sectors, a source of foreign exchange, an 
attractor of foreign investment and a means of diversifying the resource-based focus of the economy.

However various policy attempts to stimulate this sector have been of limited success. It has been postulate that one reason for the failure of these policies has been their one-sided focus on S\&T-based or radical innovation, with limited attention to the more important process (for developing countries) of DUI and incremental innovation. Furthermore the policy literature has ignored this aspect to the extent that there is little understanding of how the absorptive capacity of the sector could be improved.

This study has been an attempt to redress the gap in understanding. By analysing the dynamics of technology adoption for AM, possible weaknesses and constraints in the system have been identified. Before we discuss these outcomes, however, it is important to reconsider the salient or fundamental basics of absorption; such a discussion now follows.

The innovation literature is unambiguous on certain key principles, including that firms or more broadly business enterprises, are at the centre of innovation; that development is the consequence of learning and innovation; and most importantly that knowledge is a critical resource for innovation. As a result, access to knowledge in a developing country through the provision of the appropriate infrastructure and teaching institutions, particularly broadband communication, tertiary education and public goods, should be prioritised.

However knowledge without learning is of limited value; as a result, the most important process in development is learning. There are three recognised types of learning within systems of innovation, namely learning through DUI, learning through S\&T and formal competence building. The first two processes are located mainly in firms, whereas the latter is provided by learning organisations which therefore have a fundamental role to play in supporting innovation.

Finally innovation, whether through the absorption and implementation of new knowledge, or through the creation and commercialisation of new knowledge, is a matching process resulting from the confluence of knowledge (and particularly new knowledge) with 
opportunity, the latter mainly but not exclusively market opportunity. These matching skills are not homogeneous within a sector but are often highly concentrated within particular firms and even individuals. These firm or individuals are called early adopters and need to be both recognised and supported through appropriate policy instruments within their local systems of innovation. Failure to do so will limit the capacity of early adopters to absorb news technologies and establish the trends for follower firms.

Other aspects are also of importance in the stimulation of early absorption, including the presence of research and development within firms, connectivity between firms, universities, suppliers and consumers, the openness of innovation systems and the presence of effective government support for innovators, particularly in terms of risksharing.

These fundamental points now form the basis for developing insights from the study of AM. It has been noted in the study that many of the respondents were solely dependent on suppliers for key information, reflecting a one-sided relationship with the available knowledge basis. This aspect is particularly critical in their interaction with the senior managers within their companies who were generally resistant to expenditure on new and as yet unproven technology. A similar result was obtained in other studies (Cohen, 2014) This lack of knowledge surrounding $A M$ is a major problem and as a result it is recommended that the quantity, quality and relevance of the AM related media are improved and that this material is targeted at key decision makers within firms.

The concern over raw materials is an important outcome to the study. The extension of local research and development projects, such as the titanium beneficiation program, to include steel and other raw materials required by manufacturers will accelerate the use of AM technology in the local context (DefenceWeb, 2013) Recognising that raw material costs and availability are perceived constraints to the diffusion of AM, it is concluded that product development efforts by the CSIR and other public research institute should be focussed on formulations to allow the regular and inexpensive use of such materials within the manufacturing sector. 


\section{Conclusions}

Whether AM will eventually become a dominant technology in metal and plastic manufacturing will depend on many factors. In this case study of manufacturers within a small geographic area of Gauteng (Sebenza), it has been shown that diffusion of the technology is still in its initial stages with only $5 \%$ of the sample reporting ownership or lease of AM machines. It is useful to consider such users as early adopters who are experimenting with the technology and using it for the manufacture of prototypes rather larger-scale batch production.

The remainder of the sample are mostly unaware of, or perhaps even unconcerned about, AM and lack both knowledge and understanding of the technology. This is a critical aspect if AM becomes the revolutionary technology that has been claimed (Hyman, 2011; Sung-Won, 2013). The South African manufacturing sector could fail to derive the maximum benefit and face further loss in market share through international competition.

The extent to which these observations can be applied beyond the Sebenza cluster is a key question for the case study and its methodology. Knowledge, learning and market understanding have been cited as major factors supporting or driving innovation within economies. The weakness of all three components within this cluster is of concern, especially considering that similar concerns have been raised in previous studies (Cohen, 2014). The Department of Science and Technology has attempted to address these deficiencies through its programmes in advanced manufacturing and support for innovation. Indeed the existence of early adopters, as revealed by this study, is perhaps good evidence of the efficacy of such interventions.

The weaknesses, however, remain within the late adopters and laggards. These firms appear to underinvest in knowledge and learning to the extent that they fail to study, consider, evaluate and implement new technologies. Efforts of other agencies to encourage these activities and particularly to strengthen the DUI aspects of technology diffusion and 
innovation must be increased, failing which the much-awaited turnaround in South African manufacturing will never materialise.

\section{References}

Abenathy, W.J. and Utterback, J.M. (1978) 'Patterns of Industrial Innovation', Technology Review, Vol. 80 No. 7, pp. 40-47.

Akiike, A. (2013) 'Where is Abernathy and Utterback Model?', Annals of Bussiness Administrative Science, Vol. 12, pp. 225-236.

Azarmi, D. (2016) 'Factors Affecting Technology Innovation and Its Commercialisation in Firms', Modern Applied Science, Vol. 10 No. 7, pp. 36-48.

Bashir, A. 'Market Size: How large is the market for consumer 3D Printers?' [online] http://amirsthoughts.com/market-size-how-large-is-the-market-for-consumer-3dprinters/ (Accessed 21 June 2016).

Bass, F.M. (2004) 'A New Product Growth for Model Consumer Durables', Management Science, Vol. 50 No. 12, pp. 1825-1832.

Bass, F.M., Gordon, K., Ferguson, T.L. and Githens, M.L. (2001) 'DIRECTV: Forcasting Diffusion of a New Technology Prior to Product Launch', Interfaces, Vol. 31 No. 3, pp. S82-S93.

Bass, F.M., Gordon, K., Ferguson, T.L. and Githens, M.L. (2001) 'DIRECTV: Forecasting diffusion of a new technology prior to product launch', Interfaces, Vol. 31 No. 3_supplement, pp. S82-S93.

Brown, A.S. (2014) 'By The Numbers: A Big Forcast', Mechanical Engineering, pp. 28-29. 
Budmen, I., Rotolo, A. and Stirling, D. (2013) The book on 3D printing. Access 2013).

Caffrey, T., Campbell, I. and Wohlers, T., Wohlers Report 2016. (2016). Wohlers Associates, Fort Collins, Colarado. (Access 2016)

Campbell, R.I., De Beer, D.J. and Pei, E. (2011) 'Additive manufacturing in South Africa: building on the foundations', Rapid Prototyping Journal, Vol. 17 No. 2, pp. 156-162.

Campbell, T.A. and Ivanova, O.S. (2013) 'Additive manufacturing as a disruptive technology: Implications of three-dimensional printing', Technology \& Innovation, Vol. 15 No. 1, pp. 67-79.

Canalys (2014) '3D printing market to grow to US\$16.2 billion in 2018'.

Cohen, D., Sargeant, M. and Somers, K. (2014) '3-D printing takes shape', McKinsey Quarterly, Jan.

Cohen, D.L. (2014) 'Fostering mainstream adoption of industrial 3D printing: Understanding the benefits and promoting organizational readiness', 3D Printing and Additive Manufacturing, Vol. 1 No. 2, pp. 62-69.

Conner, B.P., Manogharan, G.P., Martof, A.N., Rodomsky, L.M., Rodomsky, C.M., Jordan, D.C. and Limperos, J.W. (2014) 'Making sense of 3-D printing: Creating a map of additive manufacturing products and services', Additive Manufacturing, Vol. 1 No. 4, pp. 64.

Davis, F.D. (1989) 'Percieved usefulness, percieved ease of use and user acceptance of information technology', Management Information Systems Research Center, University of Minnesota, Vol. 13 No. 3, pp. 319-340.

De Beer, D.J., South Africa 2007 Additive Fabrication (AF) landscape. (2008). (Access 2008) 
De Jong, J.P.J. and De Bruijn, E. (2013) 'Innovation Lessons From 3-D Printing', MITSloan Management Review, Vol. 54 No. 2, pp. 43-52.

DefenceWeb, Boeing and CSIR collaborate on titanium powder manufacturing. (2013) Aerospace Manufacturing and Design. GIE Media, New York, http://www.defenceweb.co.za/index.php?option=com content\&view=article\&id=30 811:boeing-and-csir-collaborate-on-titanium-powdermanufacturing\&catid=7:Industry\&Itemid=116. (Access 2013)

Department of Science and Technology (2012) 'Ministerial Review Committee on Science, Technology and Innovation Landscape in South Africa: Final Report', in Department of Science and Technology (Ed.), Department of Science and Technology, Pretoria.

Du Preez, W.B. (2011) 'Rapid Prototyping Technology in South Africa', Institute of Inventors and Innovators, Rapid Product Development Association of South Africa.

Du Preez, W.B. and De Beer, D.J. (2006) 'RAPDASA-A vehicle for product development technology diffusion in South Africa'.

Faulkner, D., Loewald, C. and Makrelov, K., Achieving higher growth and employment: Policy options for South Africa. (2013) South African Reserve Bank Working Paper WP/13/03. South Africa Reserve Bank, Pretoria. (Access 2013)

Geelhoed, A. (2014) '3D printing: The New Industrial Revolution That Will Change the Landscape of Credit Risk Management', Business Credit, pp. 34-37.

Hyman, P. (2011) 'Ten disruptive technologies', ASSOC COMPUTING MACHINERY 2 PENN PLAZA, STE 701, NEW YORK, NY 10121-0701 USA.

Kaplan, D. (2008) 'Science and Technology Policy in South Africa Past Performance and Proposals for the Future', Science, Technology \& Society, Vol. 13 No. 1, pp. 95-122. 
Lilien, G., Rangaswamy, A. and Van den bulte, C., diffusion Models: Managerial Applications and Software. (1999). Pennsylvania. (Access 1999)

Manyika, J., Chui, M., Bughin, J., Dobbs, R., Bisson, P. and Marrs, A. (2013) Disruptive technologies: Advances that will transform life, business, and the global economy, McKinsey Global Institute New York. Access 2013).

Mariotti, M. and Fourie, J. (2014) 'The economics of apartheid: An introduction', Economic History of Developing Regions, Vol. 29 No. 2, pp. 113-125.

Massiani, J. and Gohs, A. (2015) 'The choice of Bass model coefficients to forecast diffusion for innovative products: An empirical investigation for new automotive technologies', Research in Transportation Economics, Vol. 50, pp. 17-28.

Norton, J.A. and Bass, F.M. (1987) 'A Diffusion Theory Model of Adoption and Substitution for Successive Generations of High-Technology Products ', Management Science, Vol. 33 No. 9, pp. 1069-1086.

OECD, Review of South Africa's Innovation Policy. (2007). Organisation for Economic Cooperation and Development, Paris, http://www.oecd.org/sti/inno/oecdreviewsofinnovationpolicysouthafrica.htm. (Accessed 10 September 2015 Access 2007)

Oliveira, T. and Martins, M.F. (2011) 'Literature Review of Information Technology Adoption Models at Firm Level', The electronic Journal Information Systems Evaluation, Vol. 14 No. 1, pp. 110-121.

Robinson, B. and Lakhani, C. (1975) 'Dynamic Price Models for New-Product Planning', Management Science, Vol. 21 No. 10, pp. 1113-1122.

Rogers, E.M. (2003) Diffusion of Innovation, Simon \& Schuster, New York. Access 2003). 
Roth, S. (2014) 'The Cash is in the Medium: On the Stage Management of 3D Printing'.

Ryan, G.W. and Bernard, H.R. (2003) 'Techniques to identify themes', Field methods, Vol. 15 No. 1, pp. 85-109.

Schwab, K. and Sala-i-Martin, X., The Global Competitiveness Report 2014-2015. (2014). World Economic Forum, Geneva. (Access 2014)

Seekings, J. and Nattrass, N. (2015) Policy, politics and poverty in South Africa, Palgrave Macmillan. Access 2015).

Statistics South Africa (2016) 'Gross Domestic Product First Quarter 2016', in Africa, S.S. (Ed.), Statistics South Africa, Pretoria.

Steenhuis, H.-J. and Pretorius, L., (2015), 'Additive Manufacturing or 3D Printing and its Adoption' in Conference Additive Manufacturing or 3D Printing and its Adoption, International Association for Management of Technology, Cape Town.

Straub, E.T. (2009) 'Understanding Technology Adoption: Theory and Future Directions for Informal Learning', Review of educational research, Vol. 79 No. 2, pp. 625-649.

Sung-Won, J. (2013) 'Seven disruptive innovations for future industries', SERI Quarterly, Vol. 6 No. 3, pp. 94.

the dti 'Launch of the Industrial Policy Action Plan IPAP 2015/16 - 2017/18' [online] http://www.thedti.gov.za/editmedia.jsp?id=3312 (Accessed 15 June 2015).

The White House (2014) 'President Obama Announces Two New Public-Private Manufacturing Innovation Institutes and Launches the First of Four New Manufacturing Innovation Institute Competitions', The White House. 
Thilmany, J. (2014) 'By the Numbers: Growth by Addition', Mechanical Engineering-CIME, Vol. 136 No. 10, pp. 30-31.

Venkatesh, V., Morris, M.G., Davis, G.B. and Davis, F.D. (2003) 'User acceptance of Information Technology: Toward a Unified View', Management Information Systems Research Center, University of Minnesota, Vol. 27 No. 3, pp. 425-478.

Weller, C., Kleer, R. and Piller, F.T. (2015) 'Economic implications of 3D printing: Market structure models in light of additive manufacturing revisited', International Journal of Production Economics, Vol. 164, pp. 43-56.

Wild, S. (2014) 'SA joins 3D printing revolution'. 